
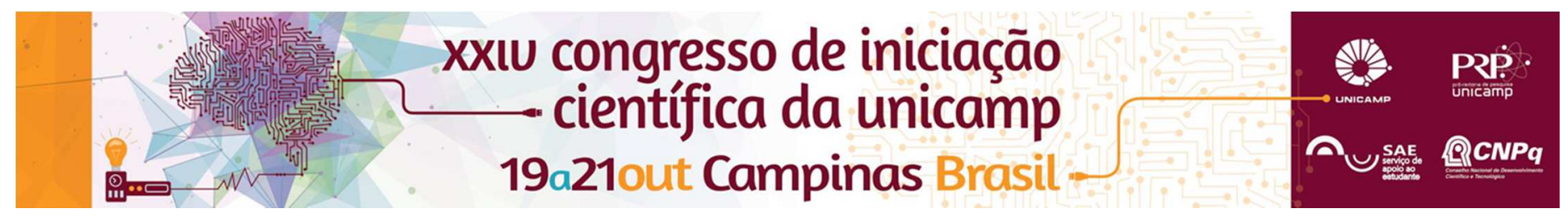

\title{
Carcinoma Odontogênico com Dentinóide: Relato de caso com descrição de uma nova entidade recentemente classificada
}

\author{
Suzana Shinomia*, Gabriel Alexandre Brandão, Homero Rodrigues dos Passos, Oslei P. de Almeida, Eliane \\ Maria Ingrid Amstalden, Albina Altemani, Fernanda Viviane Mariano.
}

\section{Resumo}

Carcinoma odontogênico com dentinóide é uma entidade recentemente descrita com poucos casos relatados na literatura. Este trabalho apresenta um caso de um paciente que apresentou esta entidade desde 2006 evoluindo com duas recidivas. Pouco se sabe ainda sobre o comportamento biológico desta neoplasia e, portanto, o objetivo do caso é acrescentar dados de um paciente que apresenta até o momento 10 anos de evolução com desconhecido comportamento.

\section{Palavra chave: \\ Carcinoma odontogênico com dentinóide, Reclassificação histopatológica, Tumor odontogênico.}

\section{INTRODUÇÃO}

Dentinóide foi definido por Gardner e Farquhar como um tecido colageneizado, geralmente não mineralizado, o qual lembra dentina, mas não contêm túbulos ou canalículos. Ele pode ou não exibir inclusões celulares e é frequentemente reconhecido como um componente de um número de tumores odontogênicos benignos, especialmente odontoma complexo, tumor de células fantasmas dentinogênico, fibrodentinoma ameloblástico, mas também podem ser encontrados em casos de tumor odontogênico adenomatóide, tumor odontogênico cístico calcificante e fibro-odontoma ameloblástico. $\mathrm{O}$ reconhecimento da maioria destas entidades é baseada em características histomorfológicas e celulares específicas e alguns dos quais não requer a presença de dentinóide para estabelecer o diagnóstico. Existem outros tumores odontogênicos produtores de dentinóide muito mais raros, com características microscópicas que não são reconhecidas na atual classificação da OMS. Entre estas lesões incomuns, estão os chamados "dentinoma", "dentinoameloblastoma", "ameloblastoma adenoide com dentinóide", "dentinoma adenomatóide" e atualmente os casos de "Carcinoma odontogênico com dentinóide". O propósito deste estudo é descrever um paciente que apresentou o Carcinoma odontogênico com dentinóide em 2006 evoluindo com duas recidivas.

\section{RESULTADOS E DISCUSSÃO}

RELATO: Paciente do gênero masculino, 50 anos comparece em consulta de rotina apresentando massa em região de maxila esquerda em 2015. O mesmo foi diagnosticado em 2006 com tumor odontogênico no local (SOE) e em 2011 apresentou nova lesão diagnosticada como Adenoma Pleomorfo. Em todos os momentos, ele foi submetido à ressecção local do tumor. $\mathrm{Na}$ avaliação histopatológica de 2015, detectou-se presença de um material eosinofílico acelular compatível com dentinóide. Este material estava rodeado por cordões estreitos e lençol de células epiteliais ovóides a poligonais em arranjo empaliçada. Estas células se apresentaram bastante uniformes com núcleos vesiculares e com ocasionais figuras de mitose. Em algumas áreas, estas células tinham um citoplasma claro e por vezes mais escamóides e/ou basofílicas. Baseado em todos estes achados, o diagnóstico de Carcinoma Odontogênico com Dentinóide foi realizado. O paciente segue em acompanhamento sem novas lesões.

\section{CONCLUSÕES}

Para o melhor de nosso conhecimento este é o sétimo caso relatado na literatura, mas o primeiro com amplo seguimento da doença. Este trabalho reforça a importância da revisão da classificação de tumores e acrescenta dados a Literatura para um maior entendimento sobre esta nova entidade.

\section{AGRADECIMENTOS}

Os autores agradecem a: Ana Cláudia Sparapani Piazza, Arethusa Souza, Fabiana Cassarotti e Luzia Magalhães Alves pela assistência técnica.

\section{Este estudo foi financiado por}

FAPESP: 2011/23204-5;

FAPESP: $2011 / 23366-5$

FAPESP: 2016/07399-4

Coordenação de Aperfeiçoamento Pessoal e de Nível Superio (CAPES-PNPD)

\section{Conflito de interesse}

Os autores declaram que não tem conflito de interesse.

\footnotetext{
1. Gardner DG, Farquhar DA. A classification of dysplastic forms of dentin. J Oral Pathol. 1979;8:28-46.

2. Barnes L, Eveson JW, Reichart P, Sidransky D, editors. World Health Organization classification of tumours. Pathology and genetics of head and neck tumours. Lyon: IARC Press; 2005. 3. Pindborg JJ. On dentinomas. Acta Pathol Microbiol Scand Suppl. 1955; 105:135-44.

4. Anker AH, Radden BG. Dentinoma of the mandible. Oral Surg Oral Med Oral Pathol. 1989;67:731-3.

5. Lukinmaa PL, Hietanen J, Laitinen J-M, Malmstro"m M. Mandibular dentinoma. J Oral Maxillofac Surg. 1987;45:60-4.

6 . Takeda Y. So-called, "immature dentinoma": a case presentation and histological comparison with ameloblastic fibrodentinoma. J Oral Pathol Med. 1994;23:92-6.

7. Minamizato T, I T, Ikeda H, Fujita S, Asahina I. Peripheral-type ameloblastic fibro-dentinoma with features of so-called "immature dentinoma'. Oral Surg Oral Med Oral Pathol Oral Radiol.

2014;117:e61-4.

8. Slabbert H, Altini M, Crooks J, Uys P. Ameloblastoma with dentinoid induction: dentinoameloblastoma. J Oral Pathol Med. 1992;21:46-8.

9. Matsumoto Y, Mizoue K, Seto K. Atypical plexiform ameloblastoma with dentinoid: adenoid ameloblastoma with dentinoid.

J Oral Pathol Med. 2001;30:251-4.
} 